\title{
DISTRIBUIÇÃO ESPACIAL DA PRECIPITAÇÃO E DA EROSIVIDADE DA CHUVA MENSAL E ANUAL NO ESTADO DO ESPÍRITO SANTO(1)
}

\author{
Carlos Rogério de Mello(2), Marcelo Ribeiro Viola ${ }^{(3)}$, Nilton Curi ${ }^{(4)}$ \& Antônio Marciano da \\ Silva ${ }^{(2)}$
}

\begin{abstract}
RESUMO
O mapeamento da erosividade da chuva e da precipitação pluvial consiste de um instrumento prático e indispensável para o planejamento do uso do solo em escalas regionalizadas, como países, Estados ou grandes bacias hidrográficas. Nesse contexto, objetivou-se neste estudo analisar a continuidade espacial do potencial erosivo da chuva e da preci pitação pluviométrica, nas escalas de tempo mensal e anual, e posterior mapeamento destas, para o Estado do Espírito Santo, visando fornecer informações básicas ao planejamento de uso e manejo sustentável do solo. Para isso, 129 estações pluviométricas foram empregadas no estudo; a erosividade da chuva foi calculada tendo-se como base equações de Fournier ajustadas para os Estados vizinhos, porém com características climáticas semel hantes. Observou-se forte estrutura de dependência espacial das variáveis regionalizadas, especialmente da erosi vidade da chuva, com predomínio do modelo de semivariograma exponencial. Quanto à preci pitação pluvial, os valores do grau de dependência espacial foram inferiores aos obtidos para a erosividade; contudo, foi possível classificar a estrutura de dependência como moderada a forte. A região do Rio Doce foi classi ficada como de "alto" a "muito alto" potencial erosi vo, cuja erosividade média anual variou de 7.000a $11.460 \mathrm{MJ} \mathrm{mm} \mathrm{ha-1}^{-1} \mathrm{~h}^{-1}$ ano-1. $^{-1}$ Nessa região, os solos, além de ocorrerem em relevo dissecado e serem pobres em nutrientes, apresentam déficit hídrico pronunciado, dificultando o estabelecimento da vegetação, e são aqueles de maior vulnerabilidade natural à erosão hídrica.
\end{abstract}

Termos de indexação: potencial erosivo da chuva, geoestatística, mapeamento, conservação do solo e da água.

\footnotetext{
(1) Recebido para publicação em 12 de março de 2012 e aprovado em 08 de outubro de 2012.

(2) Professor, Departamento de Engenharia, Universidade Federal de Lavras (UFLA), Caixa Postal 3037. CEP 37200-000 Lavras (MG). E-mail: crmello@deg.ufla.br; marciano@deg.ufla.br

(3) Professor, Universidade Federal do Tocantins, Campus Gurupi, Rua Badejós, Chácaras 69 e 72, Lote 07. Caixa Postal 66. CEP 77402-970 Gurupi (TO). E-mail: mrviola@uft.edu.br

(4) Professor Titular, Departamento de Ciência do Solo, UFLA. E-mail: niltcuri@dcs.ufla.br
} 


\author{
SUMMARY: SPATIAL DISTRIBUTION OF MONTHLY AND ANNUAL \\ RAINFALL AND RAINFALL EROSIVITY IN ESPIRITO SANTO, \\ BRAZIL
}

\begin{abstract}
The mapping of rainfall erosivity and rainfall is a practical and indispensabletool to plan thesoil and water management on a regi onal scale, such as countries, states or basins. Thepurpose of this study was to analyzethespatial continuity of erosivepotential of rainfall and rainfall, considering monthly and annual mean values, and to map them for theState of Espírito Santo, Brazil, providing basic information for the planning of sustainablesoil use and management. Tothis end, 129 weather stations wereused and monthly values of rainfall erosi vity werecalculated using F ourni er's equations. A strong spatial dependency structure was observed, especially for rainfall erosivity, with data fitting to theexponential semivariogram mode. For rainfal I, thespatial dependencedegreevalues wereslightly lower than for rainfall erosivity, however, a moderateto strong spatial dependencedegreewas obtai ned. Therainfall erosivity potential of theRio Doceregion was classified as "strong" and "very strong", varying from 7,000 to $11,460 \mathrm{MJ} \mathrm{mm} \mathrm{ha}^{-1} \mathrm{~h}^{-1}$ year-1. In this region, thenatural vul nerability to water erosion of soils with a dissected relief, low natural fertility and a pronounced water deficit hampering vegetation establishment, is higher.
\end{abstract}

Index terms: erosive potential of rainfall, geostatistics, mapping, soil and water conservation.

\section{INTRODUÇÃO}

A erosão acelerada do solo é uma das grandes preocupações ambientais no Brasil, por se tratar do mai or impacto ambiental em muitos Estados do País. O comportamento espacial e temporal das chuvas consisteno fator determinístico para o processo erosivo em áreas agrícolas, bem como no tocante aos deslizamentos de massas de solo em áreas cuja geomorfol ogia éreconhecidamentederisco, comoáreas montanhosas e de topografia íngreme, sem uma eficientecobertura vegetal.

O EstadodoEspíritoSantoestá localizadona região Sudeste do Brasil, na costa leste, com área de $45.597 \mathrm{~km}^{2}(0,53 \%$ da área total do Brasil), e apresenta sete grandes bacias hidrográficas: São Mateus, I taúnas e Barra Seca (norte e nordeste do Estado), Rio Doce (baixa bacia hidrográfica do Rio Doce), Atlântico Sudeste (centro do Estado), e I tapemi rim el tabapoana (sul esudeste do Estado). $\mathrm{O}$ Estadotem aproximadamente $70 \%$ deáreas em relevo dissecado e $30 \%$ em relevo aplainado (Atlas..., 2008). As áreas acidentadas, além de substancial variabilidade nas precipitações pluviométricas, apresentam grande variabilidade detemperatura. As áreas suavizadas tendem a se concentrar nas partes mais baixas, coincidentes com os Tabuleiros Costeiros e planícies litorâneas (restingas emanguezais), com preci pitações relativamente não muito el evadas.

O Espírito Santo faz divisa com Minas Gerais a oeste, com o Rio de J aneiro ao sul, com a Bahia ao norteeébanhado, em toda a sua faixa leste, pel ooceano Atlântico. O crescimento da economia do Estado nos últimos anos tem sido impul sionado pela exploração agrícola do solo, silvicultura e mineração. Esse processo tem levado a alguns inconvenientes da sustentabilidadeambiental, especialmentenotocante à erosão do sol o e ocorrência, cada vez mais frequente, deáreas degradadas.

O desenvol vimento demapas visandoà distribuição espacial devariáveis dimáticase, ou, derivadas destas, como o potencial erosivo da chuva, constitui-se em ferramenta indispensável ao planejamento em macroescala deatividades associadas, principal mente, à agricultura e mineração. Nesse sentido, há vários estudos desenvol vidos em muitos países objetivando o mapeamento da variável erosividade da chuva, destacando-se os trabal hos de Mannaerts \& Gabriels (2000) para Cabo Verde (África), Oduro-Afriyie(1996) para Ghana (África), Qi et al . (2000) para a Coreia do Sul, Salako (2010) para a Nigéria, M eusburger et al. (2012) para a Suíça, entre outros. Quanto ao Brasil, têm-se os estudos desenvol vidos por Silva (2004) para todo o território brasileiro, M ello et al. (2007) para o Estado deMinas Geraise Montebeller et al. (2007) para oEstadodoRiodeJ aneiro. Especialmentenos trabalhos de Meusburger et al. (2012), Mello et al. (2007) e Montebeller et al. (2007) para o desenvolvimento de mapas, foram utilizadas técnicas geoestatísticas com aplicação do interpolador krigagem ordinária.

Deacordo com Akkala et al. (2010), os quais fizeram uma vasta expl oração da literatura científica sobre o desempenho deinterpoladores espaciais, ointerpolador krigagem ordi nária éum dos mais interessantes para o mapeamento de grandezas climáticas, por conciliar efetividade estatística (variância mínima e soma dos pesos sempre iguais a 1, ou seja, ele não apresenta viés) esimplididade e por consistir de uma combi nação linear dos pesos dekrigagem, os quais são estatísticos. No entanto, conformeVieira (2000) e Goovaerts (1999), éimprescindível que haja uma modelagem eficaz do semivariograma, uma vez que todo o processo 
subsequente de interpolação depende do fato de essa model agem representar a estrutura de continuidade espacial do fenômeno em estudo. N esse aspecto, a amostragem é fator determinístico, sobretudo em pequena escala, devido à descontinuidade do semivariograma a pequenas distâncias (Isaaks \& Srivastava, 1989).

Diante do exposto, estetrabalho objetivou estudar a continuidade espacial das grandezas precipitação pluviométrica e erosividade da chuva, em escala de tempo mensal e anual, bem como produzir os respectivos mapas delas para o Estado do Espírito Santo, aplicando procedimentos degeoestatística.

\section{MATERIAL E MÉTODOS}

\section{Base de dados e cálculo da erosividade}

O cálculo da erosividade da chuva foi conduzido aplicando-se relações entre a erosividade média da chuva, em escala mensal, e o índice de Fournier modificado (MFI), conforme proposto por Renard \& Freimund (1994), as quais foram ajustadas para al gumas localidades espećficas por diferentes autores (Figura 1). Essas relações possuem a seguinte estrutura:

$$
\begin{gathered}
\mathrm{EI}_{30 \mathrm{~m}}=\mathrm{aMFI}^{\mathrm{b}} \text { ou } \mathrm{EI}_{30 \mathrm{~m}}=\mathrm{a}+\mathrm{bMFI} \\
\mathrm{MFI}=\left(\frac{\mathrm{Pm}^{2}}{\mathrm{~Pa}}\right) \\
\mathrm{EI}_{30 \mathrm{a}}=\sum_{\mathrm{m}=1}^{12}\left(\mathrm{EI}_{30 \mathrm{~m}}\right)
\end{gathered}
$$

em que $\mathrm{EI}_{30 \mathrm{~m}}$ corresponde à erosividade média do respectivo mês $\mathrm{m}$ ( $\mathrm{MJ}$ ha-1 $\mathrm{mm} \mathrm{h}^{-1}$ ), MFI éoíndice de Fournier M odificado $(\mathrm{mm}), \mathrm{P}_{\mathrm{m}}$ éa preci pitação média do mês $\mathrm{m}(\mathrm{mm}), \mathrm{P}_{a}$ éa precipitação média anual $(\mathrm{mm})$, $\mathrm{EI}_{30 \mathrm{a}}$ corresponde à erosividade média anual ea eb são os coefi cientes deajuste da equação. Com baseem dados médi os de preci pitação mensal ede preci pitação média anual, cal culados a partir de séries históricas constituídas por dados diários de precipitação, cal culam-se os valores mensais deMFI. A partir desses valores, ecom base na equação mais apropriada para cada posto pluviométrico (Figura 1), estima-se a erosividade mensal com a respectiva relação $\mathrm{EI}_{30 \mathrm{~m}} \mathrm{X}$ MFI. A soma dos valores médios mensais deerosi vidade fornece seu valor médio anual. É importanterealçar queessas equações devem ser aplicadas para estimativa de val or es médios mensais de erosividade da chuva, os quais são real izados com base em dados médios de preci pitação, necessitando-se de pelo menos 10 anos consecutivos de dados de precipitação diária para cál cul o da média dos respectivos val ores mensais e do valor médio anual de precipitação.

O procedimento decál culo da erosividade utilizando equações baseadas no MFI tem si do bastantecomum quando se visa ao desenvolvimento de mapas de erosividade, devido à pequena quantidade de estações pluviográficas no território brasilei ro como um todo, (Silva, 2004; Mello et al., 2007; Salako, 2010). Em particular, no Estado do Espírito Santo, há apenas quatro estações meteorológicas do Instituto Nacional de Meteorologia (INMET) com séries históricas representativas; portanto, a disponibilidade de séries de erosividade oriundas de pluviogramas no Estado fica limitada, dificultando o mapeamento dessas grandezas sem a aplicação do conceito desenvolvido com base no índice de Fournier modificado (MFI).

Na figura 1 está apresentado o mapa do Estado do EspíritoSanto, com a distribuição espacial dos postos pl uviométricos apl icados ao estudo da erosividade da chuva e da preci pitação, cujos dados foram extraídos doHidroweb/ANA econsistem apenas de dados diários de precipitação (total de 129 estações), bem como da identificação, para cada posto pluviométrico, das equações que foram aplicadas nos cál cul os assodiados à erosividade da chuva a partir do MFI. As estações pluviométricas foram selecionadas tendo-se como base a representatividade das séries históricas, em termos temporais (foram buscadas séries com pel omenos 10 anos dedados) equeestas fossem atuais. Assim, al guns postos pluviométricos, para os quais o monitoramento sofreu interrupções permanentes, com as séries sendo finalizadas na década de 1980, não foram empregados no estudo.

NoE stado do Espírito Santo existem sete grandes badias hidrográficas (Figura 1), conformeapresentado anteriormente. Para efeito de apresentação dos resultados ediscussões comparativas destes, optouse, nestetrabalho, por um agrupamento por regiões, da seguinteforma: São Mateus (São Mateus, I taunas e Barra Seca), Rio Doce, I tapemirim/I tabapoana e Atlântico Sudeste. Às duas últimas regiões incluemseas áreas de serra do Estado. Para cada uma destas regiões foram aplicadas equações do tipo $E_{30 \mathrm{~m}}=f$ (MFI) desenvolvidas em outros Estados, porém procurando-se associá-las às condi ções cl imáticas do Estado do E spírito Santo, uma vez que essa condição éfundamental para ouso dessetipo de equação. Assim, para a região do Rio Doce foi aplicada a equação desenvol vida por Oliveira et al. (2009) especificamente para a bacia do Rio Doce, noEstado de Minas Gerais; para a região São Mateus, foi usada a equação apresentada por Silva (2004) para J uazeiro (BA), visto que as condições ambientais são semel hantes, como déficit hídricomais pronunciado, elevada concentração de chuvas e temperaturas médias anuais mais elevadas; especificamente para as áreas de serra do Estado, foi aplicada a equação desenvolvida por Carvalho et al. (2005) para a região serrana do Rio do J aneiro; epara as demais áreas das regiões ItapemirimI tabapoana eAtlântico Sudeste, induindotoda a região litorânea delas, foi aplicada a equação desenvol vida por Carvalho et al. (2005) para Seropédica (RJ ), dada a similaridade das condições litorâneas ecl imáticas destes Estados. 


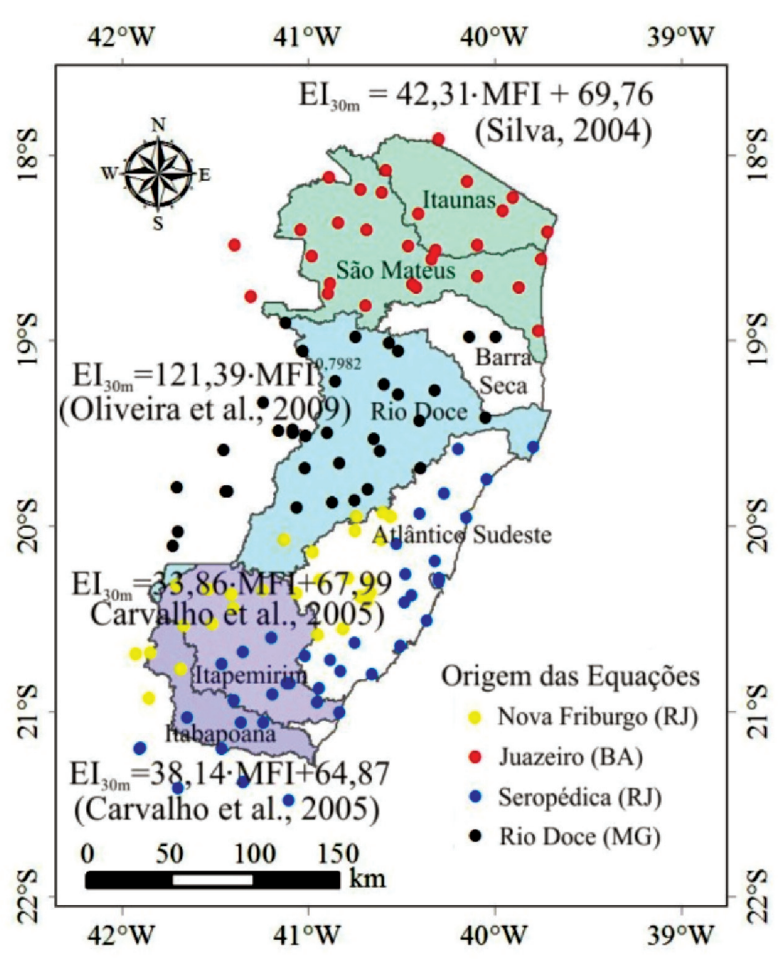

Figura 1. Princi pais bacias hidrográficas do Estado do Espírito Santo, distribuição espacial dos postos pluviométricos empregados no estudoe respectivas equações $\mathrm{EI}_{30 \mathrm{~m}} \times \mathrm{MFI}$ aplicadas e respectivos autores.

\section{Análise geoestatística}

A identificação de tendências regionalizadas é extremamente importante para a continuidade dos processos em geoestatística, uma vez quea existência dessas tendências significa que é provável haver mascaramento da estrutura de dependência espacial, o que, segundo Clark (1979), pode levar a uma falsa dependência espacial dos dados. A identificação de tendências e a posterior remoção delas foram executadas, conforme RibeiroJ unior \& Diggle(2001), aplicando-se o software R, com o pacote de geoestatística GeoR.

A pós essas análises preliminares assodiadas à base de dados, procedeu-se ao desenvolvimento dos semivariogramas experimentais, permitindo avaliar o comportamento das semivariâncias como função da distância, ou seja, se há continuidade espacial dos dados. Essa etapa é fundamental para definir qual model o teórico de semi variograma é mais apropriado para representar a estrutura de autocorrelação espacial. Assim, os modelos exponencial, esférico e gaussiano foram testados aplicando-se o método dos mínimos quadrados ponderados, eajustes a ol ho foram também aplicados para corrigir possíveis distorções que métodos automáticos proporcionam (AnguloMartinez et al., 2009). Após análise do ajuste dos model os ao semivariograma experimental, estes foram selecionados com base na validação cruzada e na análise visual do ajuste, especial mente notocanteao comportamentodos parâmetros efeito pepita ealcance (Vieira, 2000; Lyon et al., 2010). O software GeoR também foi aplicado nas etapas descritas. Os mapas foram gerados com basena krigagem ordinária e, para garantir mel hor qualidade destes, o programa ArcMap (ESRI, 2004) foi aplicado com base no modelo de semivariograma previamenteajustado.

\section{RESULTADOS E DISCUSSÃO}

\section{Comportamento médio da precipitação pluviométrica e da erosividade da chuva}

Na figura 2a estãoapresentados gráficos nos quais sepodeanalisar a distribuição mensal da preci pitação média e da respectiva erosividade média, nas quatro regiões representativas do Estado do Espírito Santo (F igura 1). Em todas as regiões é possível distinguir dois períodos específicos, sendo um chuvoso, entre outubro e março (verão), e outro caracteristicamente mais seco, com totais médios mensais inferiores a $30 \mathrm{~mm}$, entre abril e setembro (inverno). Essa característica é marcantedas condições cl imáticas do Sudeste do Brasil, devido à influência do Anticiclone do Atlântico Sul, que se intensifica entre julho e setembro, influenciando a presença de frentes frias, e também em razão da menor ou mesmo inexistente presença de umidade oriunda da região amazônica, a qual é responsável tanto pela formação da Zona de Convergência do Atlântico Sul (ZCAS) quanto por linhas deinstabilidade (chuvas convectivas) na região Sudeste do Brasil (Reboita et al., 2010).

O mês mais chuvoso e com maior erosividade média, em todas as regiões, é dezembro, seguido por novembro ejaneiro, nessa ordem. A concentração de chuvas noverãoé especial mente destacada na região do Rio Doce, onde 80,8 \% do total preci pitado ocorre entre outubro e março. Nas demais, tem-se menor percentual, sendo de 75,6 \% para Itapemirim/ I tabapoana, 77,1 \% para São M ateus e 70,9 \% para o Atlântico Sudeste. Notocanteà erosi vidade, épossível observar maior concentração temporal do que para preci pitação. NoRio Doce, 90,2 \% do potencial erosivo está vinculadoaos eventos de preci pitação queocorrem nos referidos meses (outubro-março). Nas outras regiões, tem-se $81 \%$ para I tapemirim/l tabapoana, 83,9 \% para São Mateus e 80,1 \% para o Atlântico Sudeste, a qual engl oba parte importante da região serrana do EspíritoSanto.

Em termos do comportamento anual da preci pitação e da erosividade (F igura 2b), observa-se queas regiões do Rio Docee São Mateus apresentam totais anuais semel hantes em termos de preci pitação (aproximadamente $1.100 \mathrm{~mm}$ ), enquanto a região I tapemirim/I tabapoana apresenta $1.270 \mathrm{~mm}$ e o Atlântico Sudeste, $1.429 \mathrm{~mm}$. No contexto da 
(a)

Rio Doce
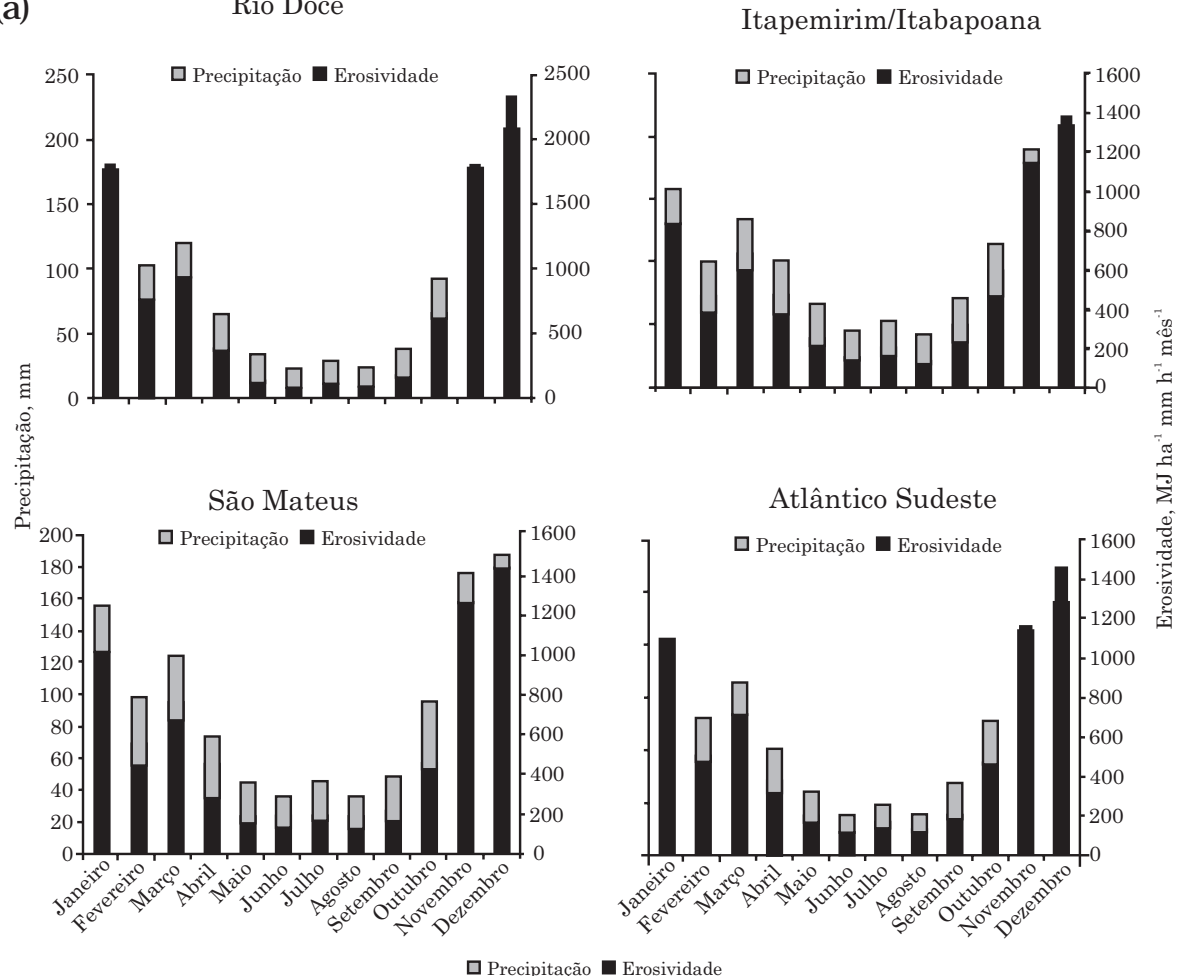

(b)

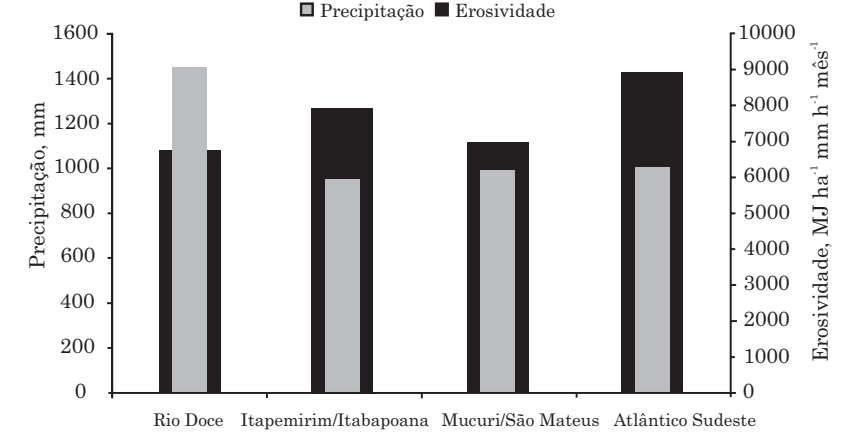

Figura 2. Distribuição média mensal (a) e anual (b) da precipitação e erosividade da chuva para as quatro regiões do E stado do E spírito Santo consi deradas neste estudo.

erosividade anual, a região do Rio Doce é a que apresenta o maior valor médio anual (>9.000 MJ $\mathrm{ha}^{-1} \mathrm{~mm} \mathrm{~h}^{-1}$ ), enquanto nas demais regiões esse val or é próximo a $6.000 \mathrm{MJ} \mathrm{ha}^{-1} \mathrm{~mm} \mathrm{~h}^{-1}$. Contudo, é importante destacar que esses valores são médias para as regiões eque podem existir sub-regiões com valores mais altos ou mais baixos. Somente a distribuição espacial permitirá identificar com maior precisão esse comportamento.

\section{Continuidade espacial da erosividade da chuva e da precipitação}

O comportamento dos semivariogramas experimental eteórico, para a erosividade da chuva e para a precipitação, ambas anuais, no Estado do Espírito Santo, está apresentado na figura 3. É importante destacar, avaliando os respectivos semivariogramas experimentais, a existência de dependência espacial de ambas as variáveis, especial mente para a erosividade. $\mathrm{O}$ ajuste do model o teórico de semivariograma produziu grau de dependência de $100 \%$ para essa variável, caracterizado pelo efeito pepita zero. Isso significa que o comportamento da semivariância como função da distância está sendo devidamentecaptado pelo modelo, ou seja, de crescimento até um determinado limite, conhecido como patamar, gerando um alcance de $251,5 \mathrm{~km}$. O model o exponencial foi o escol hido para ambas as variáveis devido à capacidade dele de descrever o comportamento da semivariância em detrimento dos model os esférico egaussiano, os quais também foram testados, porém esses ajustes não produziram resultados satisfatóri os para as condições amostrais trabal hadas.

Analisando o comportamento de modelos de semivariograma para estudos relacionados à 
distribuição espacial de precipitações intensas no Estado deMinas Gerais, Melloet al. (2008) conduíram pela melhor performance do modelo exponencial. Entretanto, Goovaerts (1999), analisando o comportamento da erosividade na região de Algarve (Portugal), aplicou o model o esférico etambém obteve bom ajuste, sem, contudo, fazer comparações entreos modelos. Estudandoa erosividade da chuva noEstado deMinas Gerais, Melloet al. (2007) também aplicaram os modelos exponencial e esférico e obtiveram supremacia do primeiro, ponderando, noentanto, sobre o bom desempenho do modelo esférico para as condições estudadas. Montebeller et al. (2007), estudando a distribuição espacial da $\mathrm{EI}_{30}$ anual noEstado do Rio J aneiro, também aplicaram omodeloexponencial para modelar a continuidade espacial da erosividade, obtendo bons ajustes, mas sem testar outros model os. Silva et al . (2010) aplicaram os model os gaussiano e exponencial para modelar a continuidade espacial da $\mathrm{EI}_{30}$ mensal e anual noleste de Minas Gerais (bacia do Rio Doce) e obtiveram adequado desempenho de ambos, porém com superioridadedo model o gaussiano. Observa-se, portanto, que há diferentes estudos visando à espacialização da preci pitaçãoeerosividade da chuva em diferentes condições e que não há uma definição específica sobre qual modelo deve ser recomendado; contudo, a aplicação do modelo exponencial é notoriamente mais frequentee aceita.

Os semivariogramas ajustados para a erosividade e precipitação mensais estão apresentados nas figuras 4, 5 e6, para os meses de janei roa abril, maio a agosto e setembro a dezembro, respectivamente. Para essa situação, o model o gaussianotambém produziu al guns bons ajustes, especificamente para as erosividades mensais relativas ao período seco (junho-agosto) epara o mês de novembro. Contudo, houve supremacia do model o exponencial, o qual produziu ajustes de alta qualidade, semelhantes aos da modelagem da continuidade espacial da erosividade anual. O modelo de semivariogramas que mais se destacou relativamenteà preci pitaçãotambém foi o exponencial, com exceção dos meses deagosto (Figura $5 \mathrm{~d}$ ) esetembro (Figura 6a), seguindo a lógica obtida para a erosividade no que diz respeito ao melhor comportamento do model o gaussiano para os meses do período seco.

No tocante à erosividade, os al cances estimados pel os model os de semi variogramas foram superiores aos gerados pel os model os ajustados para precipitação, além de mel hor estrutura de continuidade espacial , o que pôde ser comprovado pelos valores do grau de dependência espacial (GD) sempre superiores a $60 \%$, além da análise visual destes (Vieira, 2000). Os al cances para a erosividademensal variaram de 126,1 a 296,2 km. É importante destacar que os maiores alcances foram obtidos para os meses mais chuvosos, durante os quais há predominância da Zona de Convergência do Atlântico Sul (ZCAS) no Estado do Espírito Santo; essefenômeno meteorológico atinge grandes áreas, podendo influenciar todo o Estado duranteum único episódio, induzindo a dependência espacial dos fenômenos associados à preci pitação, uma vez que há mai or semel hança do regime pluvial entre as diferentes regiões doE stado.

A análisevariográfica da preci pitação mensal para oEstado doEspírito Santo estimou alcances, deforma geral, menores do que para a erosividade (de 61,7 a $291,6 \mathrm{~km}$ ), bem como o comportamento geral do GD. Essa situação caracteriza uma estrutura de continuidadeespacial inferior, embora marcante, para todos os meses do ano, exceção feita ao mês de novembro.

Apesar das dificuldades inerentes ao ajuste de modelos de semivariogramas no tocante às suas características estruturais associadas ao comportamento das semi variâncias como função da distância eà observância das hipóteses estacionárias deprimeira esegunda ordens, conformerelatam Vieira (2000) e Lee (1997), é importante destacar os
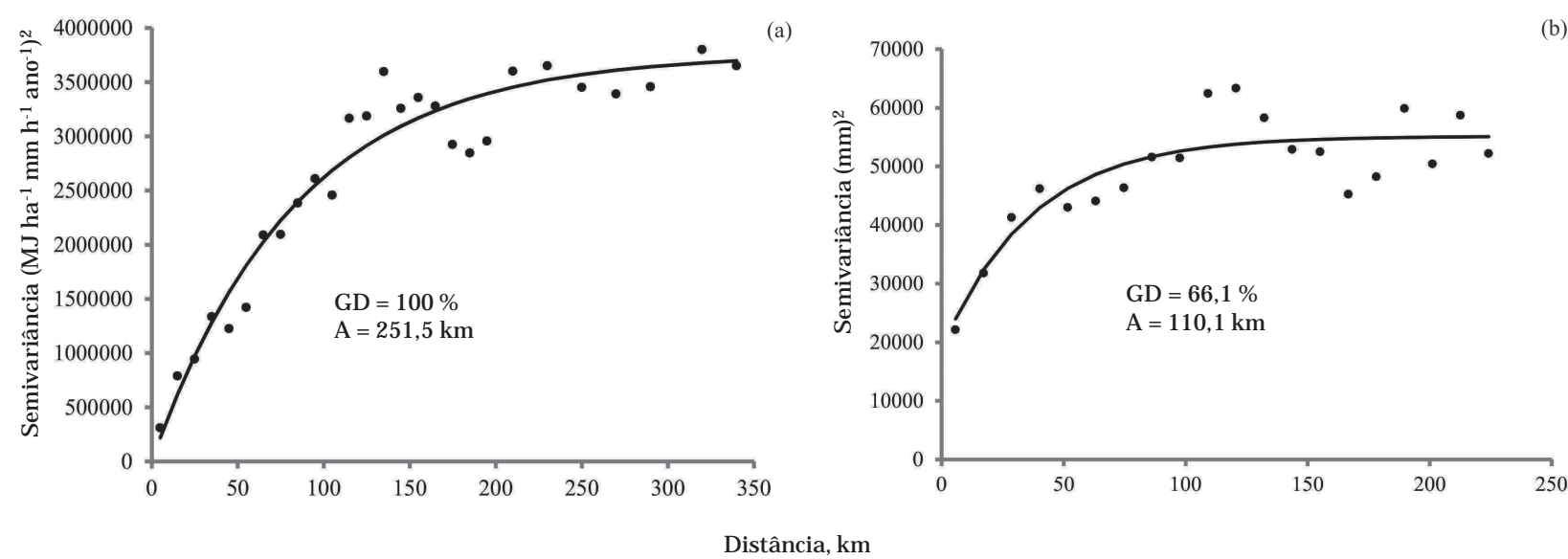

Figura 3. Semivariogramas ajustados para a erosi vi dade anual (a) e preci pitação anual (b) para o Estado do Espírito Santo (GD: grau de dependência espacial). 

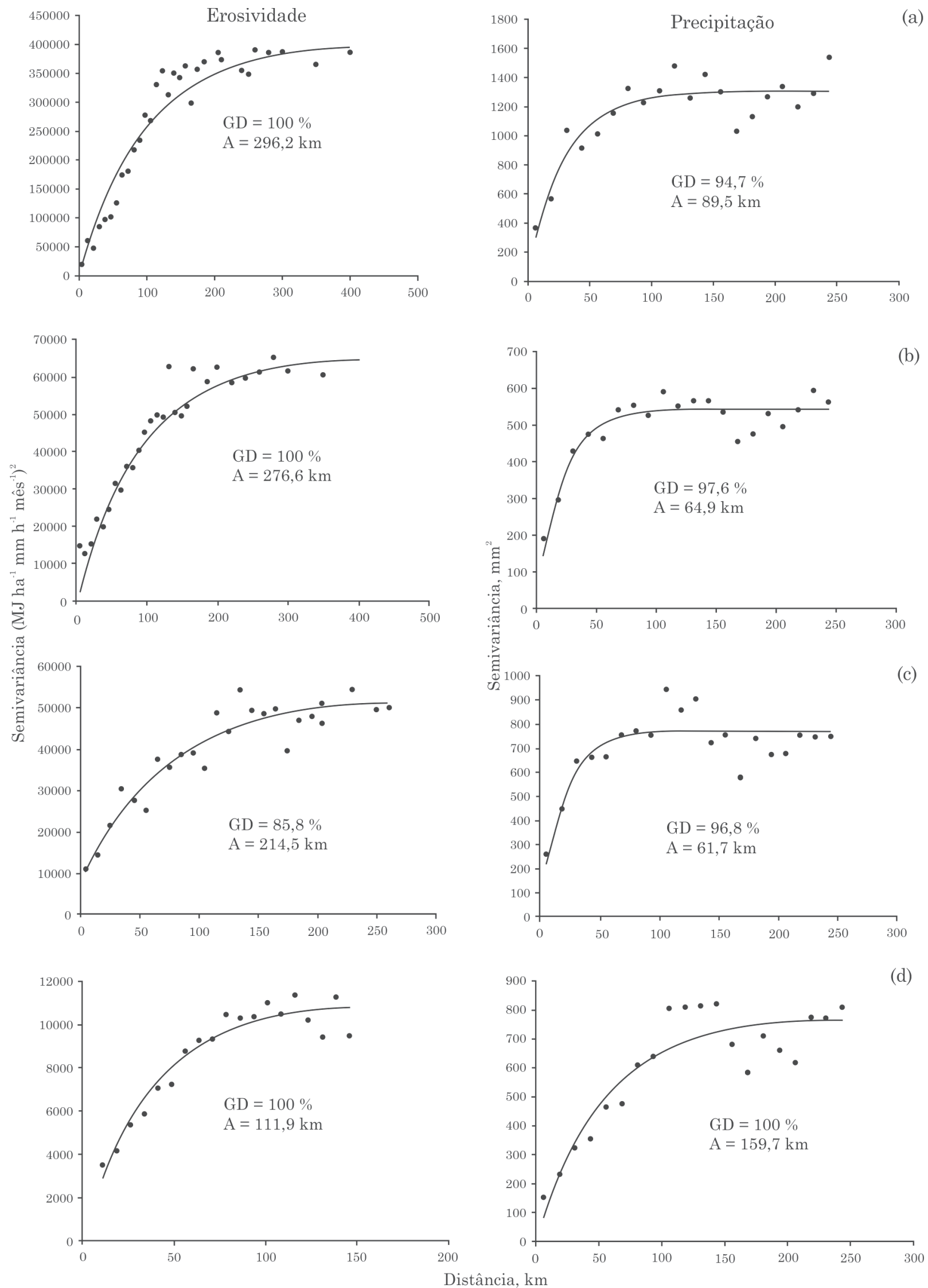

Figura 4. Semivariogramas ajustados para a erosividade e preci pitação mensais para o Estado do Espírito Santo (a) janeiro; (b) fevereiro; (c) março; (d) abril. 

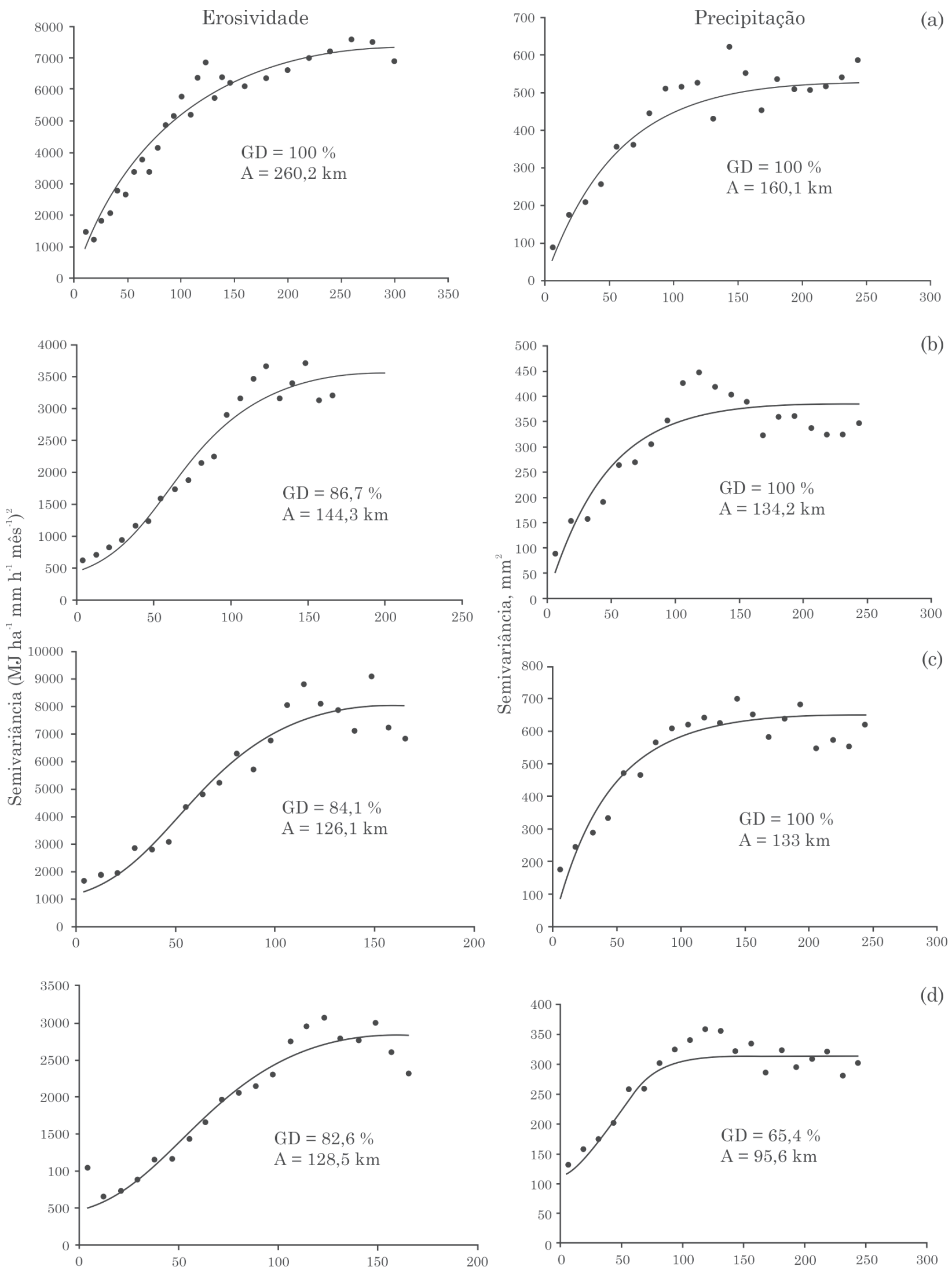

Distância, $\mathrm{km}$

Figura 5. Semivariogramas ajustados para erosi vidade e preci pitação mensais para o Estado do Espírito Santo (a) maio; (b) junho; (c) julho; (d) agosto. 

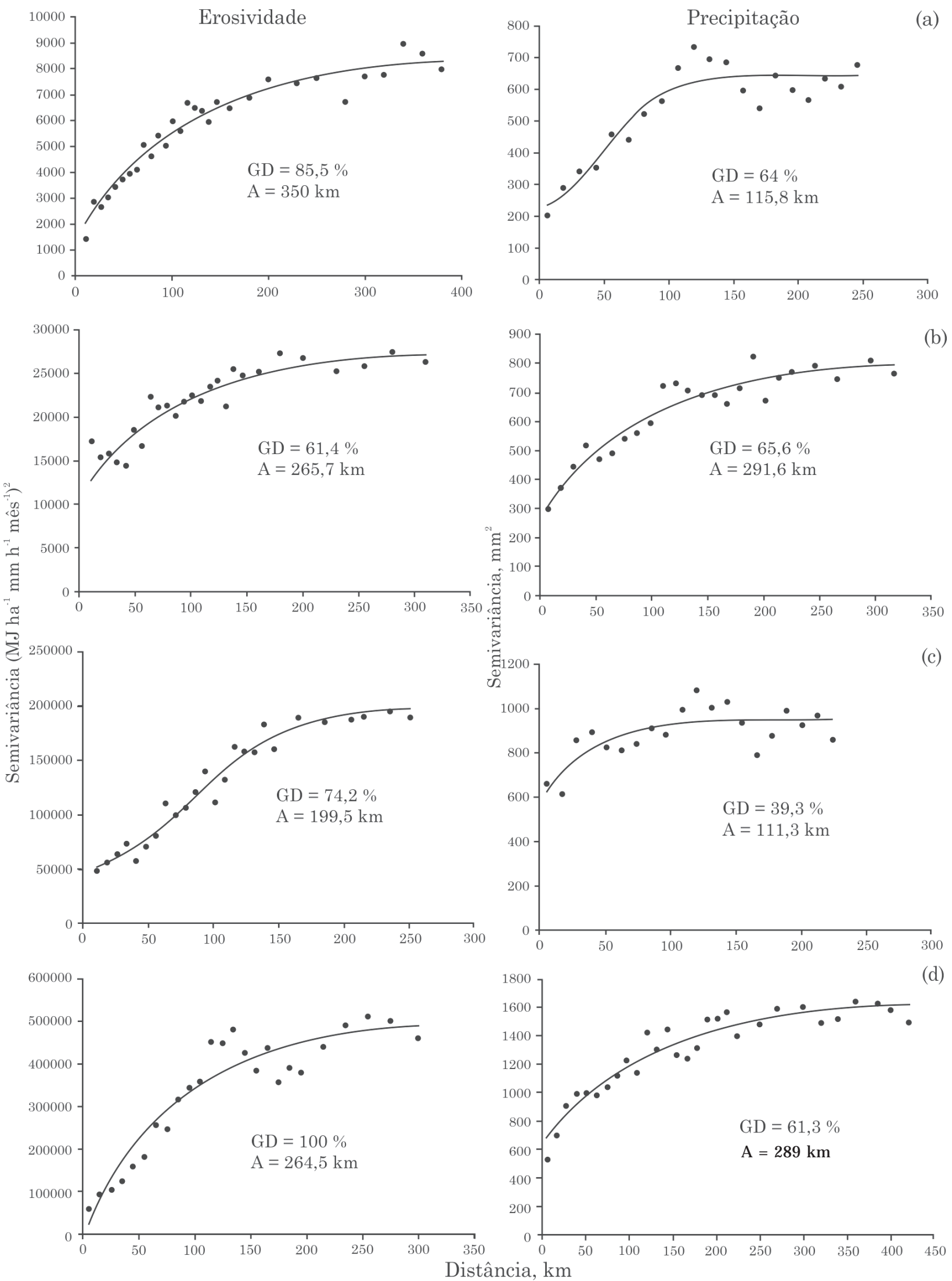

Figura 6. Semivariogramas ajustados para erosividade e preci pitação mensais para o Estado do Espírito Santo (a) setembro; (b) outubro; (c) novembro; (d) dezembro. 
adequados ajustes obtidos, com descrição matemática da estrutura de continuidadeespacial para ambas as variáveis. I sso significa que a geração de mapas de boa qualidade, tanto para a erosividadequanto para a precipitação, é plausível, permitindo descrever espacial mente duas grandezas fundamentais para o planejamento emanejo sustentável dosolo eda água noreferido Estado.

\section{Mapeamento da precipitação e erosividade da chuva}

A distribuição espacial da erosividade da chuva (a), esta mesma distribuição, porém seguindo a classificação proposta por F oster et al. (1981) (b), eda precipitação (c), ambas anuais, para o Estado do Espírito Santo, está apresentada na figura 7. Observase que a região do Rio Doce é a que apresenta os maiores valores de erosividade anual, variando de pouco mais de 7.000 até $11.460 \mathrm{MJ} \mathrm{ha}^{-1} \mathrm{~mm} \mathrm{~h}^{-1} \mathrm{ano}^{-1}$, com grande concentração de valores superiores a 8.287 $\mathrm{MJ} \mathrm{ha}^{-1} \mathrm{~mm} \mathrm{~h}^{-1}$ ano $^{-1}$. Essa constatação permite enquadrar a região, predominantemente, comotendo forte a muito forte potencial erosivo; contudo, não apresenta os maiores totais anuais de preci pitação do E stado do E spírito Santo, os quais oscilam entre 768 e $1.148 \mathrm{~mm}$, aumentando à medida que se aproxima do litoral. Mello et al. (2008), mapeando chuvas máximas com duração de 30 ' $\left(I_{30}\right)$ no Estado deMinas Gerais, observaram que, na região sob influência do RioDoce, entreas latitudes de 18 e 19으, foi verificada a predominância dos maiores valores, significando que o seu regime pluvial possui um dos mais altos potenciais erosivos do Estado.

Com basenos dados levantados, épossível constatar quea região do Rio Doce no Estado do Espírito Santo éa que apresenta a maior concentração de chuvas e queesse fato propicia a formação de eventos com maior poder erosivo. A formação de eventos de preci pitação mais concentrados nessa região é explicada pela presença marcante da Zona de Convergência do Atlântico Sul (ZCAS), a qual, segundo Reboita et al . (2010), éo principal agentecausador de precipitações intensas em boa parte do Sudeste do Brasil, especialmente entre novembro ejaneiro. De acordo com Kodama (1992), que anal isou o comportamento tanto da ZCAS quanto da Zona de Convergência do Pacífico Sul (ZCPS), a primeira atua especialmente numa faixa delatitudes entre 15 e 180S, significando que sua presença no Sudeste do Brasil é especialmente relevante nesta faixa de latitudes, provocando maior concentração de chuvas. É importantemencionar ainda queos eventos dechuvas convectivas também têm grande importância nos aspectos relacionados à erosividade e que sua formação, nas condições do E stado do Espírito Santo, é altamente rel evante, tendo em vista as el evadas temperaturas predominantes no Estado, bem comoa influência adicional do oceano Atlântico como uma das fontes principais de umidade.

Ainda no que concerneà erosividade anual, para a região do Rio Doce no Estado de Minas Gerais, Mello et al. (2007) caracterizaram-na com val ores entre9.810 e $12.050 \mathrm{MJ} \mathrm{ha}^{-1} \mathrm{~mm} \mathrm{~h}^{-1} \mathrm{ano}^{-1}$, também trabalhando com geoestatística. Além disso, Silva et al. (2010), estudando especificamente a região do Rio Doce em Minas Gerais, obtiveram valores deerosividadeanual, oriundos deanálise depluviogramas, variando de 8.000 a $16.000 \mathrm{MJ} \mathrm{ha}^{-1} \mathrm{~mm} \mathrm{~h}^{-1} \mathrm{ano}^{-1}$, assim como Oliveira et al. (2009), que obtiveram val ores deaté $13.000 \mathrm{MJ}$ $\mathrm{ha}^{-1} \mathrm{~mm} \mathrm{~h}^{-1}$ ano-1 $^{-1}$ para a mesma região. Todos estes estudos demonstram o el evado potencial erosivo das chuvas na região do Rio Doce, apesar de os totais anuais de precipitação serem inferiores aos deoutras regiões do Estado do Espírito Santo. (a)

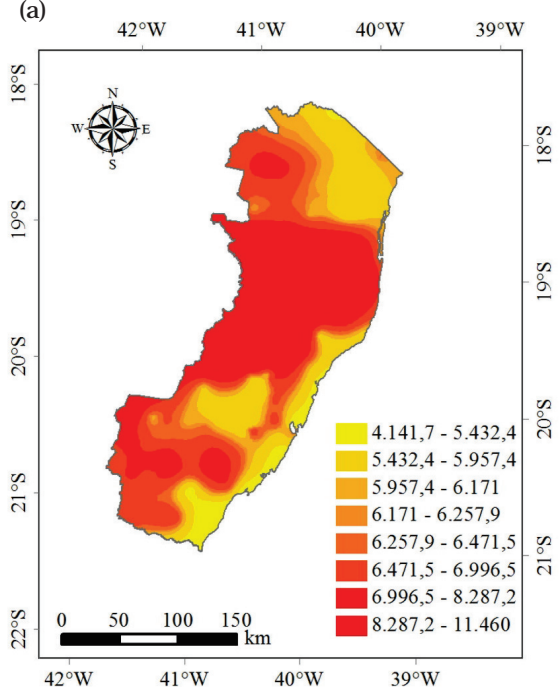

(b)
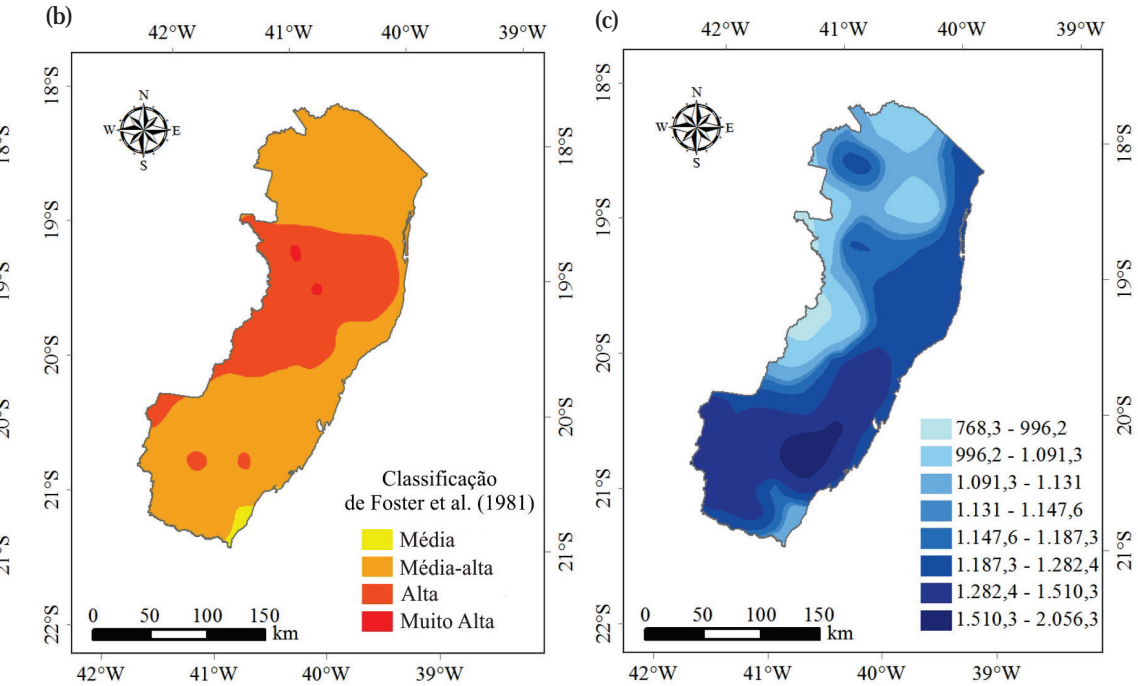

Figura 7. Mapas de erosividade anual (MJ mm ha-1 $\left.\mathrm{h}^{-1} \mathrm{ano}^{-1}\right)(\mathrm{a})$, de erosividadeanual conforme classificação de F oster et al. (1981) (b) e precipitação anual $(\mathrm{mm})(\mathrm{c})$, para o E stado do E spírito Santo. 
Em parte da região I tapemirim/l tabapoana, especificamente na divisa com o Estado do Rio de J aneiro, foram obtidos val ores de erosividade anual inferiores aos do Rio Doce, apesar de os totais anuais de preci pitação serem superiores, especial mente nas áreas deserra desta regiãoenoseu litoral. Esses valores deerosi vidadevariaram de 4.142 (na divisa com o Rio de J aneiro) a mais de 8.287,2 $\mathrm{MJ} \mathrm{ha}^{-1} \mathrm{~mm} \mathrm{~h}^{-1}$ ano-1 $^{-1}$ (nas áreas de serra), permitindo enquadrar a região como tendo moderado potencial erosivo pela classificação de F oster et al. (1981), em grande parte de sua área. Analisando a distribuição espacial da erosividade anual para o Estado do Rio de J aneiro, Montebeller et al. (2007) encontraram val ores entre 2.000 e6.000 MJ ha-1 $\mathrm{mm} \mathrm{h}^{-1} \mathrm{ano}^{-1}$ para a regiãonorte deste Estado, também trabal hando com abordagem geoestatística, porém com intensidade amostral inferior à do presente estudo. Portanto, os valores obtidos para o sul do Espírito Santo (exceção das regi ões de serra) são compatíveis com os obtidos pel o trabalho de Montebeller et al. (2007), apesar de os referidos autores terem obtido por inter polação, em al guns pontos, val ores inferiores.

Para as áreas de serra do Espírito Santo, encontradas nas regiões I tapemirim/l tabapoana e AtlânticoSudeste, foram observados valores oscilando de 4.141 a 8.287 MJ mm ha-1 $\mathrm{h}^{-1} \mathrm{ano}^{-1}$, permitindo um enquadramento de "moderado" potencial erosivo. No entanto, os totais anuais de preci pitação variaram de 1.282 a $1.510 \mathrm{~mm}$, indicando mel hor distribuição dos eventos de chuva do que para a região do Rio Doce. Esse comportamento encontra subsídio teórico nos trabal hos de Meusburger et al. (2012), os quais analisaram a distribuição espacial da erosividade, usando geoestatística, para a Suíça; Nel et al. (2010), que estudaram o comportamento da $\mathrm{EI}_{30}$ na região montanhosa da África do Sul; e Mello et al. (2012), que estudaram o comportamento da erosividade da chuva em regiões montanhosas do Estado de Minas Gerais. Em todos estes estudos foi verificada mel hor distribuição temporal da preci pitação causada pela influência da altitude, a qual promovea ocorrência de temperaturas mais amenas e, como consequência, menor pressão desaturação devapor d'água, reduzindo o potencial para eventos convectivos mais intensos.

Os menores val ores deerosividadeanual, bem como de preci pitação anual, foram observados para a região São Mateus (norte do Espírito Santo), os quais variaram de 4.142 a $6.258 \mathrm{MJ} \mathrm{ha}^{-1} \mathrm{~mm} \mathrm{~h}^{-1} \mathrm{ano}^{-1}$, e, para precipitação, foram registrados valores inferiores a $1.091 \mathrm{~mm}$ anuais, com exceção da sua faixa litorânea. Contudo, a região pode também ser enquadrada, em grande parte, como tendo moderado potencial erosivo. Para a região nordeste de Minas Gerais, quefaz divisa com a referida região do Espírito Santo, Melloetal. (2007) verificaram baixos valores anuais deerosividade: inferiores a 5.000 MJ ha-1 $\mathrm{mm} \mathrm{h}^{-1} \mathrm{ano}^{-1}$, os quais são simi lares aos obtidos no presenteestudo. Esta região, conforme Carvalho et al. (2008), trabalhando no âmbito do Zoneamento EcológicoE conômi co de Minas Gerais, apresenta totais anuais de preci pitação inferiores a 1.000 mm, com el evada demanda evapotranspirativa, ou seja, uma região com clima ti picamentesubúmido. No entanto, nãose pode desconsiderar ofato dequea região podeser afetada por eventos de precipitação com al to impacto no comportamento da erosão hídrica dosolo, devidoao fato dequehá uma tendência, semel hanteà do Rio Doce, de concentração das chuvas em apenas al guns meses do ano- aspecto desuma importância para planejamento deações visandoà sustentabilidadeambiental.

A distribuição espacial da erosividade e da precipitação, ambas mensais, para oEstadodoE spírito Santo está apresentada nas figuras 8, 9 e 10, para janeiro a abril, maioa agosto e setembro a dezembro, respectivamente. É possível notar, na figura $8(a, b, c)$ e na figura $10(\mathrm{c}, \mathrm{d})$, que os maiores valores mensais de $\mathrm{EI}_{30}$ foram obtidos para a região do Rio Doce, ou seja, especificamente nos meses mais chuvosos, a referida região apresenta os val ores mais el evados. Essa situação é ainda mais nítida para dezembro (Figura 10d), janeiro e março (Figura 8a,c). Esse comportamentoéexplicado pela intensificação da ZCAS sobreo Sudeste do Brasil, especial mentenas latitudes que delimitam a região do Rio Doce, conforme comentado. No entanto, é importante destacar que nesteperíodo há concentraçãosignificativa deumidade, bem como temperaturas el evadas, além da proximidade com o litoral, o que significa condições atmosféricas apropriadas para a formação deeventos de chuva convectivos, os quais apresentam alto potencial erosivo devido à sua curta duração e alta intensidade. Os valores de $\mathrm{EI}_{30}$ para os meses mencionados, na região do Rio Doce, variaram de 1.710 a $3.480 \mathrm{MJ} \mathrm{ha}^{-1} \mathrm{~mm} \mathrm{~h}^{-1} \mathrm{ano}^{-1}$, sendo dezembroo mês mais chuvoso e com maior erosividade. Situação semel hante, tanto em termos da distribuição espacial quanto de val ores da erosividade, foi observada por Mello et al. (2007) na região leste de Minas Gerais, com destaque para os meses de dezembro, novembro ejaneiro, nessa ordem.

Os mapas de preci pitação mensal, durante overão e início do outono (janeiro-maio), apresentaram predominância dos maiores totais mensais para a região Atlântico Sudeste, especialmente nas áreas de serra; à medida que o período de outono-inverno avança, a faixa litorânea passa a apresentar os maiores val ores de preci pitaçãoe, como consequência, os mai ores valores deerosi vidade. Essefato deve-seà presença deumidadeoriunda do oceano Atlântico, mas que, devidoà intensificação do Anticiclonedo Atlântico Sul na direção oeste (Reboi ta et al., 2010), fica restrita à faixa litorânea, fazendo com que no Estado do Espírito Santo haja um período seco mais característico na sua faixa oeste, engl obando as regiões do Rio Doce e São Mateus, além das áreas de serra das regiões I tapemi rim/I tabapoana eAtlânticoSudeste.

Tendocomo base os mapas gerados para erosividade da chuva e precipitação, ambos em escala anual e 

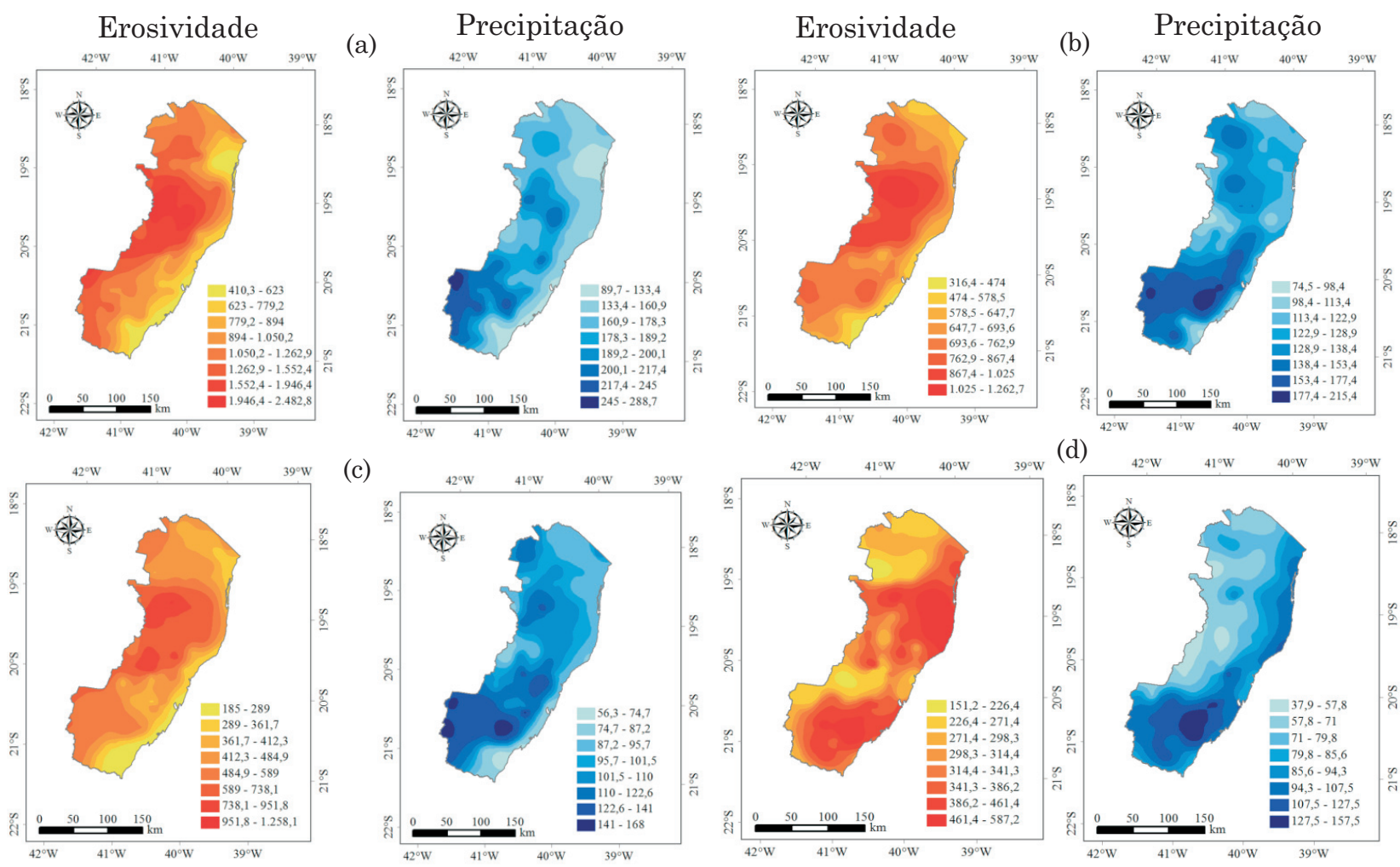

Figura 8. Mapas de erosi vidade (MJ $\mathrm{mm} \mathrm{ha-1}^{-1} \mathrm{~h}^{-1}$ ano-1), e precipitação ( $\mathrm{mm}$ ), ambos mensais, para o Estado do Espírito Santo (a) janeiro; (b) fevereiro; (c) março; (d) abril.
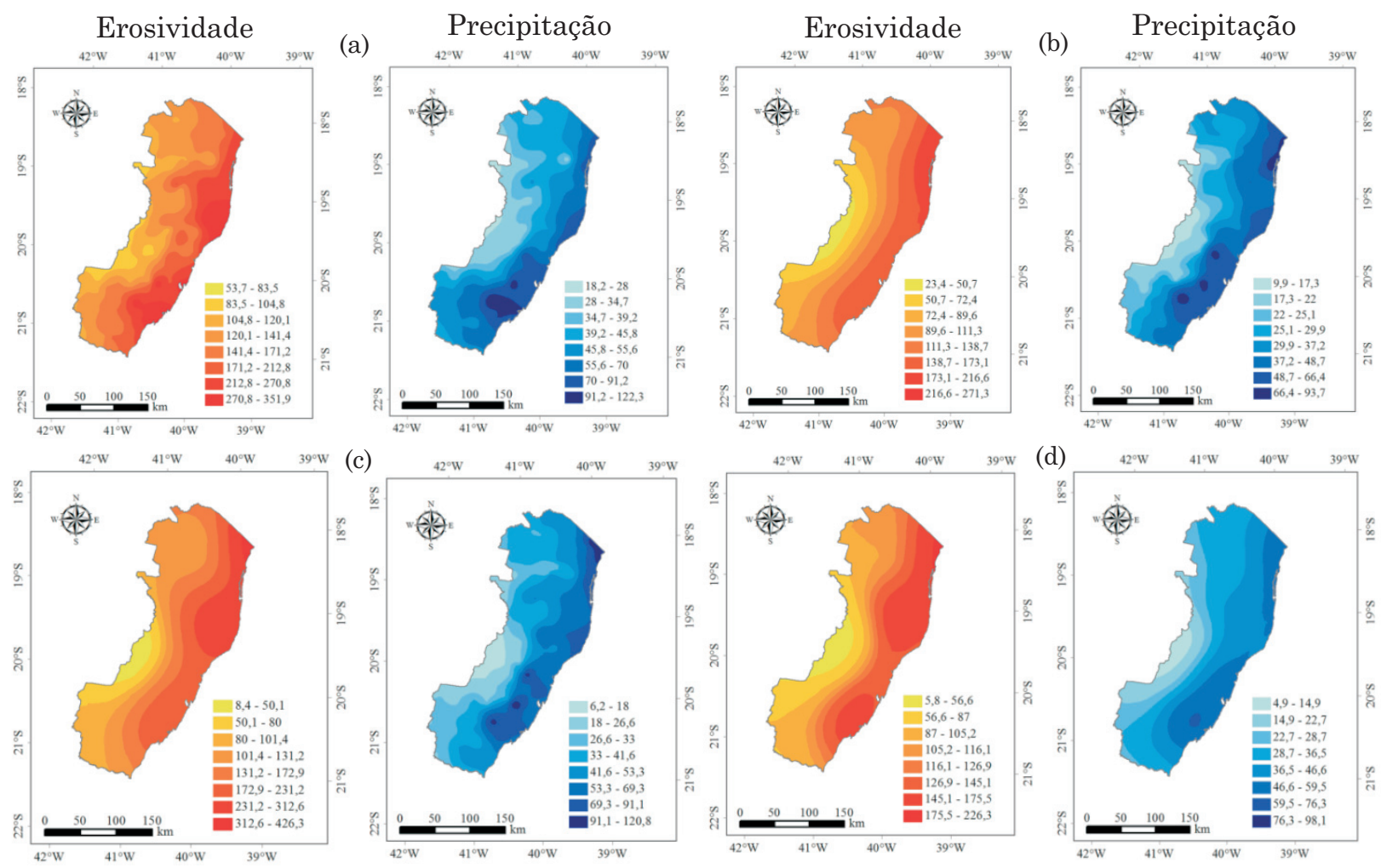

Figura 9. Mapas de erosividade (MJ ha-1 $\mathrm{mm} \mathrm{h}^{-1}$ ano-1) e preci pitação ( $\mathrm{mm}$ ), ambos mensais, para o Estado do Espírito Santo (a) maio; (b) junho; (c) julho; (d) agosto. 


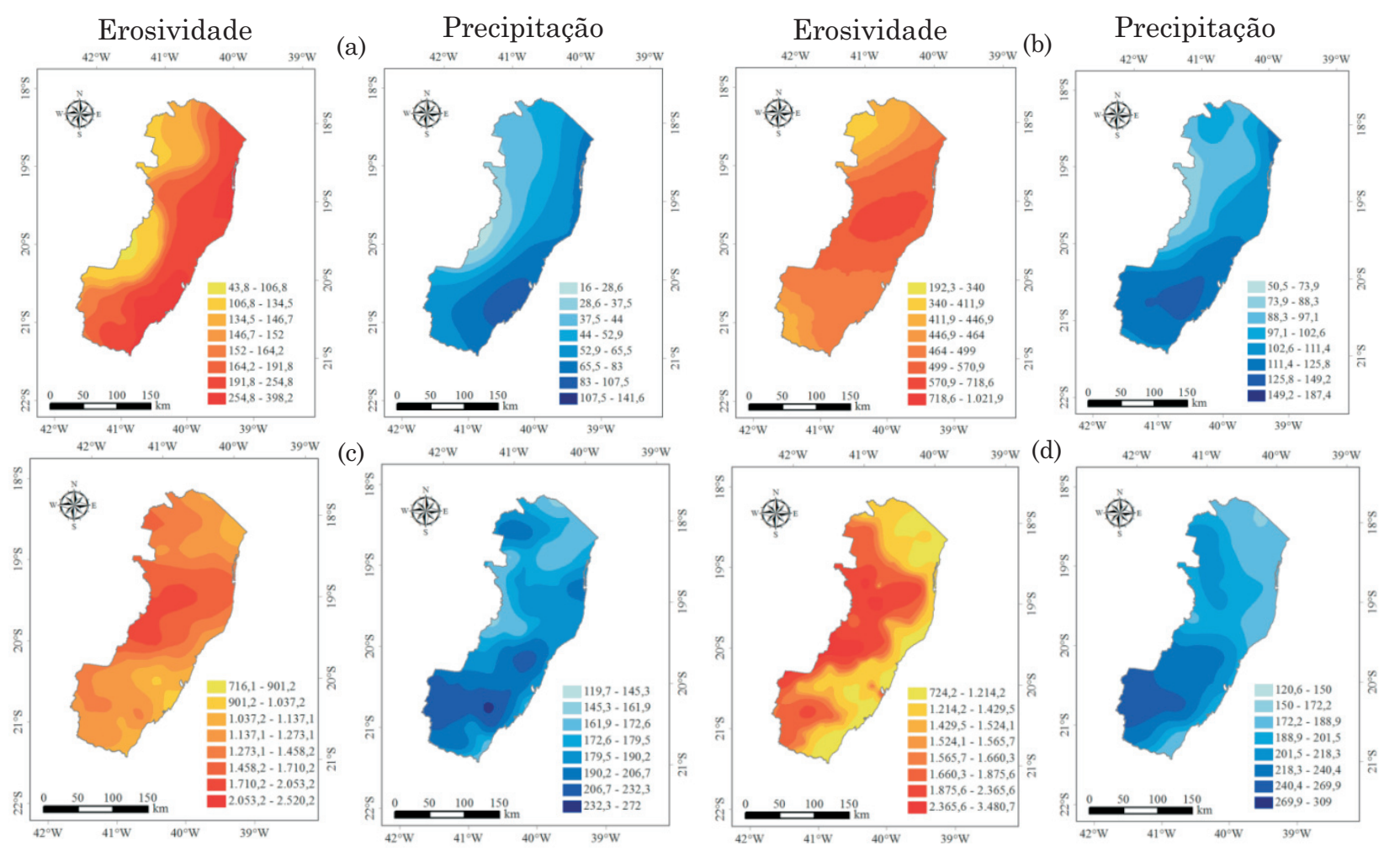

Figura 10. Mapas de erosi vidade (MJ ha-1 $\mathrm{mm} \mathrm{h}^{\mathbf{1}}$ ano-1) e preci pitação ( $\mathrm{mm}$ ), ambos mensais, para o Estado do Espírito Santo (a) setembro; (b) outubro; (c) novembro; (d) dezembro).

mensal, oEstado do Espírito Santo éespecialmente vulnerável na região do Rio Doce, a qual apresenta o mais al to potencial erosivo das chuvas. Nessesentido, este trabalho identifica espacialmente áreas cujo regime pluvial é particularmente preocupante durante o verão, fornecendo subsídios para o planejamento, em macroescala, do uso e manejo sustentável do solo, bem como para implementação de ações de conservação do sol o e da água com ênfase na condição de sol os em rel evo dissecado e pobres em nutrientes e que apresentam déficit hídrico pronunciado, dificultando o estabel ecimento da vegetação e implicando maior vulnerabilidade natural à erosão hídrica. Esses solos são principalmente Latossolos Vermelho-Amarelos, profundos, bastante degradados (áreas desnudas de topo e voçorocas esparsamente distribuídas nas paisagens) e cobertos principalmente por pastagens (F eitoza et al., 2001; Atlas..., 2008).

\section{CONCLUSÕES}

1. O comportamento espacial da erosividade da chuva e da preci pitação pluviométrica no Estado do Espírito Santoapresentou estrutura de continuidade espacial de moderada a forte, podendo ser caracterizada pelos model os de semivariograma exponencial egaussiano.
2. A região do Rio Doce apresentou o maior valor deerosividadeanual, sendo possível enquadrá-la como tendo "forte" a "muito forte" potencial erosivo; esta região apresenta áreas com sol os acidentados, pobres em nutrientes ecom maior déficit hídrico, dificultando o estabel ecimento da vegetação, merecendo mai ores cuidados conservacionistas; as demais regiões apresentaram valores inferiores, com potencial erosivo enquadrado como "moderado".

3. Apesar da maior erosividade, as regiões do Rio Docee São Mateus apresentaram os menores val ores anuais e mensais de preci pitação; as áreas de serra e parte da região Atlântico Sudeste mostraram os maiores valores de precipitação, além de melhor distribuição desta noverão.

\section{LITERATURA CITADA}

AKKALA, A.; DEVABHAKTUNI, V. \& KUMAR, A. Interpolation techniques and associated software for environmental data. Environ. Progress Sust. Energy, 29:134-141, 2010.

ANGULO-MARTINEZ, M.; LÓPEZ-VICENTE, M.; VICENTESERRANO, S.M. \& BEGUERÍA, S. Mapping rainfall erosivity at a regional scale: a comparison of interpolation methods in the Ebro Basin (NE Spain). Hydrol. Earth Syst. Sci., 13:1907-1920, 2009. 
ATLAS DE ECOSSISTEMAS DO ESPÍRITO SANTO. Vitória, Sema/Niçosa, MG, Universidade Federal de Viçosa, 2008. 504p.

CARVALHO, L.G.; OLIVEIRA, M.S.; ALVES, M.C.; VIANELLO, R.L.; SEDIYAMA, G.C.; CASTRO NETO, P. \& DANTAS, A.A.A. Clima. In: SCOLFORO, J.R.S.; CARVALHO, L.M.T. \& OLIVEIRA, A.D., eds. Zoneamento Ecológico-E conômico de Minas Gerais: Componentes geofísico e biótico. Lavras, Universidade Federal de Lavras, 2008. p.89-102.

CARVALHO, D.F.; MONTEBELLER, C.A.; FRANCO, E.M.; VALCARCEL, R. \& BERTOL, I. Padrões de precipitação e índices de erosividade para as chuvas de Seropédica e Nova Friburgo, RJ . R. Bras. Eng. Agric. Amb., 9:7-14, 2005.

CLARK, I. Practical geostatistics. London, Applied Science Publishers, 1979. 128p.

ENVIRONMENTAL SYSTEMS RESEARCH INSTITUTE ESRI. ArcGIS 9: Getting started with ArcGIS. Redlands, 2004. 265p.

FOSTER， G.R.; MCCOOL， D.K.; RENARD, K.G. \& MOLDENHAUER, W.C. Conversion of the universal soil Ioss equation to SI metric units. J. Soil Water Conserv., 36:355-359, 1981.

GOOVAERTS, P. Using elevation to aid the geostatistical mapping of rainfall erosivity. Catena, 34:227-242, 1999.

FEITOZA, H.N.; MOLENAAR, M.; MEIJ ERE, T. \& STUIVER, J. Spatial data modelling for GIS application. In: FEITOZA, L.R.; STOCKING, M.S. \& RESENDE, M., eds. Natural resources information systems for rural devel opment - approaches for Espírito Santo State, Brazil. Vitória, Incaper, 2001. p.147-173.

ISAAKS, E.H. \& SRIVASTAVA, R.M. An introduction to applied geostatistics. New York, Oxford University Press, 1989. 560p.

KODAMA, Y.M. Large-scale common features of subtropical precipitation zones (the Baiu frontal zone, the SPCZ, and the SACZ). Part I: Characteristics of subtropical frontal zones. J. Meteorol. Soc. J apan, 70:813-835, 1992.

LEE, S. Geostatistical model validation using orthonormal residuals. KSCE J . Civil Eng., 1:59-66, 1997.

LYON, S.W.; SORENSEN, R.; STENDAHL, J \& \& SEIBERT, J . Using landscape characteristics to define an adjusted distance metric for improving kriging interpolations. Inter. J. Geogr. Inf. Sci., 24:723-740, 2010.

MANNAERTS, C.M. \& GABRIELS, D. Rainfall erosivity in Cape Verde. Soil Tillage Res., 55:207-212, 2000.

MELLO, C.R.; NORTON, L.D.; CURI, N. \& YANAGI, S.N.M. Sea surface temperature (SST) and rainfall erosivity in the Upper Grande River Basin, Southeast Brazil. Ci. Agrotec., 36:53-59, 2012.
MELLO, C.R.; VIOLA, M.R.; MELLO, J .M. \& SILVA, A.M. Continuidade espacial de chuvas intensas no Estado de Minas Gerais. Ci. Agrotec., 32:532-539, 2008.

MELLO, C.R.; SÁ, M.A.C.; CURI, N.; MELLO, J .M. \& VIOLA, M.R. Erosividade mensal e anual da chuva no Estado de Minas Gerais. Pesq. Agropec. Bras., 42:537-545, 2007.

MEUSBURGER， K.; STEEL， A.; PANAGOS， P.; MONTANARELLA, L. \& ALEWELL, C. Spatial and temporal variability of rainfall erosivity factor for Switzerland. Hydrol. Earth Syst. Sci., 16:167-177, 2012.

MONTEBELLER, C.A.; CEDDIA, M.B.; CARVALHO, D.F.; VIEIRA, S.R. \& FRANCO, E.M. Variabilidade espacial do potencial erosivo das chuvas no Estado do Rio de J aneiro. Eng. Agríc., 27:426-435, 2007.

NEL, W.; REYNHARDT, D.A. \& SUMNER, P.D. Effect of altitude on erosive characteristics of concurrent rainfall events in the northern KwaZulu-Natal Drakensberg. Water SA, 36:509-512, 2010.

ODURO-AFRIYIE, K. Rainfall erosivity map for Ghana. Geoderma, 74:161-166, 1996.

OLIVEIRA, F.P.; SILVA, M.L.N.; CURI, N.; SILVA, M.A. \& MELLO, C.R. Potencial erosivo da chuva no Vale do Rio Doce, região Centro-Leste do Estado de Minas Gerais primeira aproximação. Ci. Agrotec., 33:1569-1577, 2009.

QI, H.; GANTZER, C.J .; JUNG, P.K. \& LEE, B.L. Rainfall erosivity in the Republic of Korea. J . Soil Water Conserv., 55:115-120, 2000.

REBOITA, M.S.; GAN, M.A.; ROCHA, R.P. \& AMBRIZZI, T. Regimes de precipitação na América do Sul: uma revisão bibliográfica. R. Bras. Meteorol., 25:185-204, 2010.

RENARD, K.G. \& FREIMUND, J.R. Using monthly precipitation data to estimate the R-factor in the revised USLE. J . Hydrol., 157:287-306, 1994.

RIBEIRO J UNIOR, P.J . \& DIGGLE, P.J . GeoR: A package for geostatistical analysis. R. News, 1:15-18, 2001.

SALAKO, F.K. Development of isoerodent maps for Nigeria from daily rainfall amount. Geoderma, 156:372-378, 2010.

SILVA, A.M. Rainfall erosivity map for Brazil. Catena, 57:251259, 2004.

SILVA, M.A.; SILVA, M.L.N.; CURI, N.; MARQUES, J J .G.S.M.; MENEZES, M.D. \& LEITE, F.P. Avaliaçãoe espacialização da erosividade da chuva no Vale do Rio Doce, região Centro-Leste do Estado de Minas Gerais. R. Bras. Ci. Solo, 34:1029-1039, 2010.

VIEIRA, S.R. Geoestatística em estudos de variabilidade espacial do solo. In: NOVAIS, R.F.; ALVAREZ V., V.H. \& SCHAEFER, C.E.G.R., eds. Tópicos em ciência do solo. Viçosa: Sociedade Brasileira de Ciência do Solo, v.1, 2000. p.1-54. 